\title{
Creative
}

\section{Private Citizenship: Real Estate Practice in Palestine}

\author{
Athar Mufreh \\ Architect, New York, NY, USA; amufreh@gmail.com \\ Received: 7 July 2017; Accepted: 15 August 2017; Published: 31 August 2017
}

What is the function of the new towns and real estate developments in Palestine?

The context of the West Bank serves as a unique example of the workings of real estate in an occupied territory, while considering real estate as a fundamental tool for globalization and the most critical infrastructure for urban development. The new tools that were introduced there in the mid-1990s-planned neighborhoods, title deeds, new land registrations, ownership contracts, mortgages, banks, and new sources of capital-now constitute a real estate infrastructure integral to the West Bank's development. Rawabi, the first master-planned Palestinian city, is pioneering the mechanics and experience of this global transnational infrastructure.

The evolution of a global real estate market under occupation has become the dominant spatial practice in the West Bank as well as the leading force for the Palestinian economy. The Palestinian Authority's reforms since 1994, aggravated by continual political shifts that created a diffused system of actors, have allowed real estate developers to gain power due to the unclear distribution of tasks, power structures, and territorial sovereignty. The private sector became the governing power, the authority. These private companies use 'real estate infrastructure' to help impose and dictate a conclusive idea of comfort and stability within an imagined reality. This reality is imagined by certain actors from peace envoys and Israel. It is made possible through real estate communities of individual members which 'invent nations where they do not exist' and seek refuge away from the chaotic conditions of the absence of a nation-state. Most of the planning and ideologies of these new communities, if not all of them, enable an even deeper occupation to take hold by reproducing its mechanisims.

What is key here is the sovereignty and who is governing. These emerging suburban communities of Palestine, especially Rawabi, have embodied a distinct territorialization of citizenship or 'spatial governmentality' based on contractual associations such as Home Owner Associations, replicating the American real estate model. These neighborhoods are usually governed by private developers and the individual owners themselves; a situation in which the state does not, or cannot, intervene, and rights and duties are enforced by the governing body or private developers. This explains the distinction between 'members' of contemporary real estate developments in the West Bank-their rights, duties, and relations-and the imposed non-citizen status of Palestinians in the nation-state framework.

With the unresolved status of the Palestinian state, globalization and neoliberal policies are paving the way for a surprising form of Palestinian citizenship. 'Global market citizenship', which can be considered a transnational citizenship, is a form of membership in the economic world of real estate and its financial, social, and cultural protocols. Furthermore, as the territorialization of the Palestinian state has been stalled, the global market is in a way offering a form a citizenship to Palestinians, providing a simulation, substitution, or an alternative to their envisioned modern nation-state. Lacking a nation-state of their own, but slowly becoming subjects of the market, Palestinians living in such new developments are gaining a citizenship defined by their new status as global consumers under occupation. 


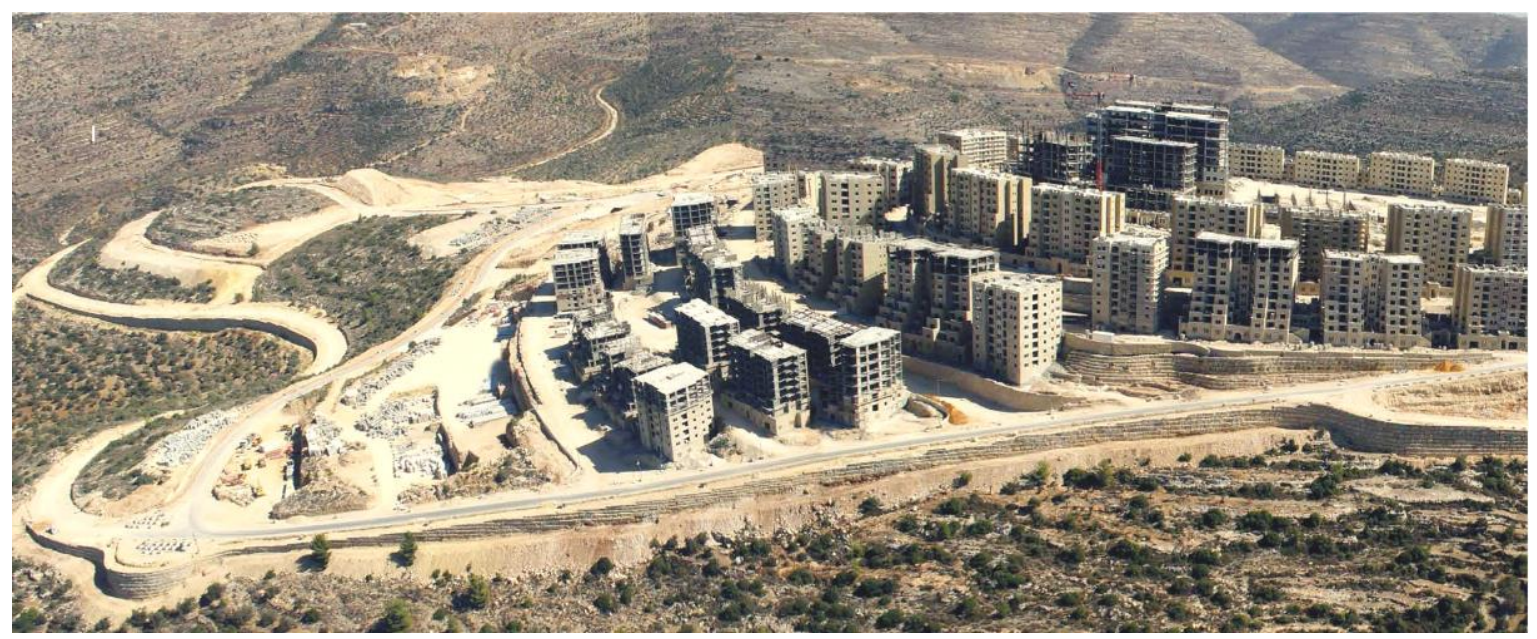

View of Rawabi in 2013: Located north of Ramallah, Rawabi is a new city promoted as a national project. Apart from the Israeli settlements, Rawabi is the first large-scale private sector land development project of its kind in Palestine. Created by a joint venture between a Palestinian-American businessman and the Qatari government, Rawabi's political, legal, environmental, material, and economic effects readily assemble a full house of actors, policies, and controversy. Image Source: Rawabi Newsletter 2013. 


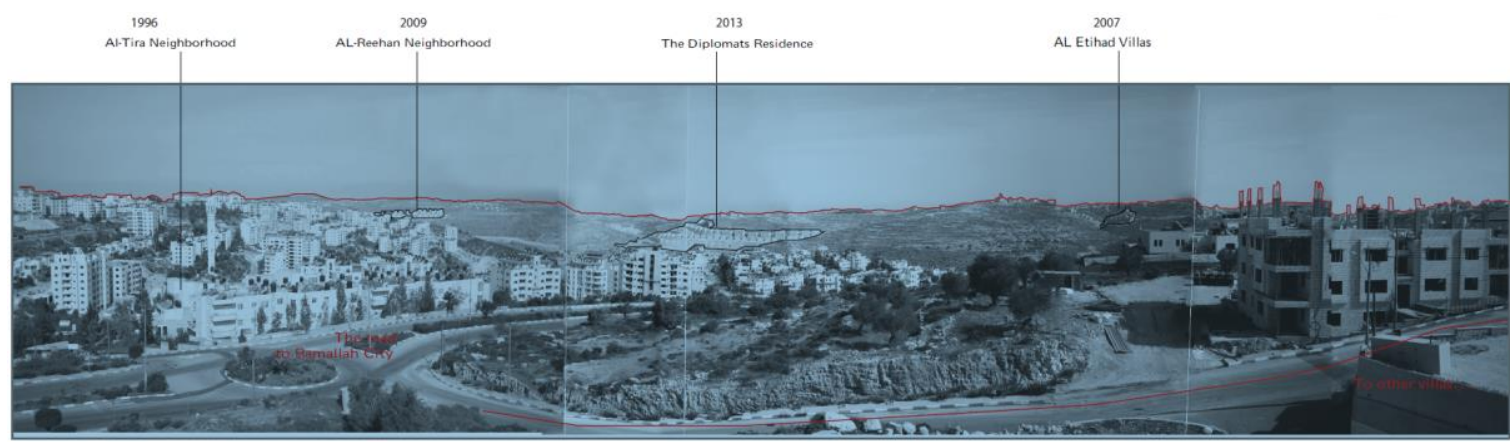
Panorama of Al- Tira neighborhood. A new expansion of Ramallah city, the image shows -as
appears in the background- examples of the new neighborhoods on the preiphery.
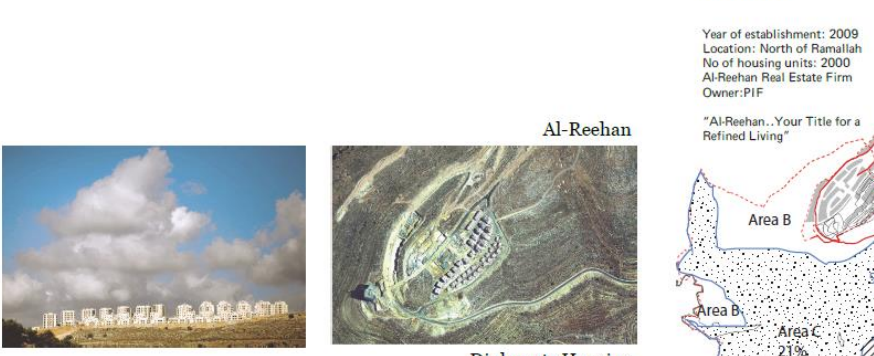

Diplomats Housing

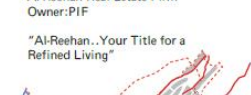
Year of establishment: 2010
Diplomats Residence
Location North t Ramalah
No of housing units: 2000
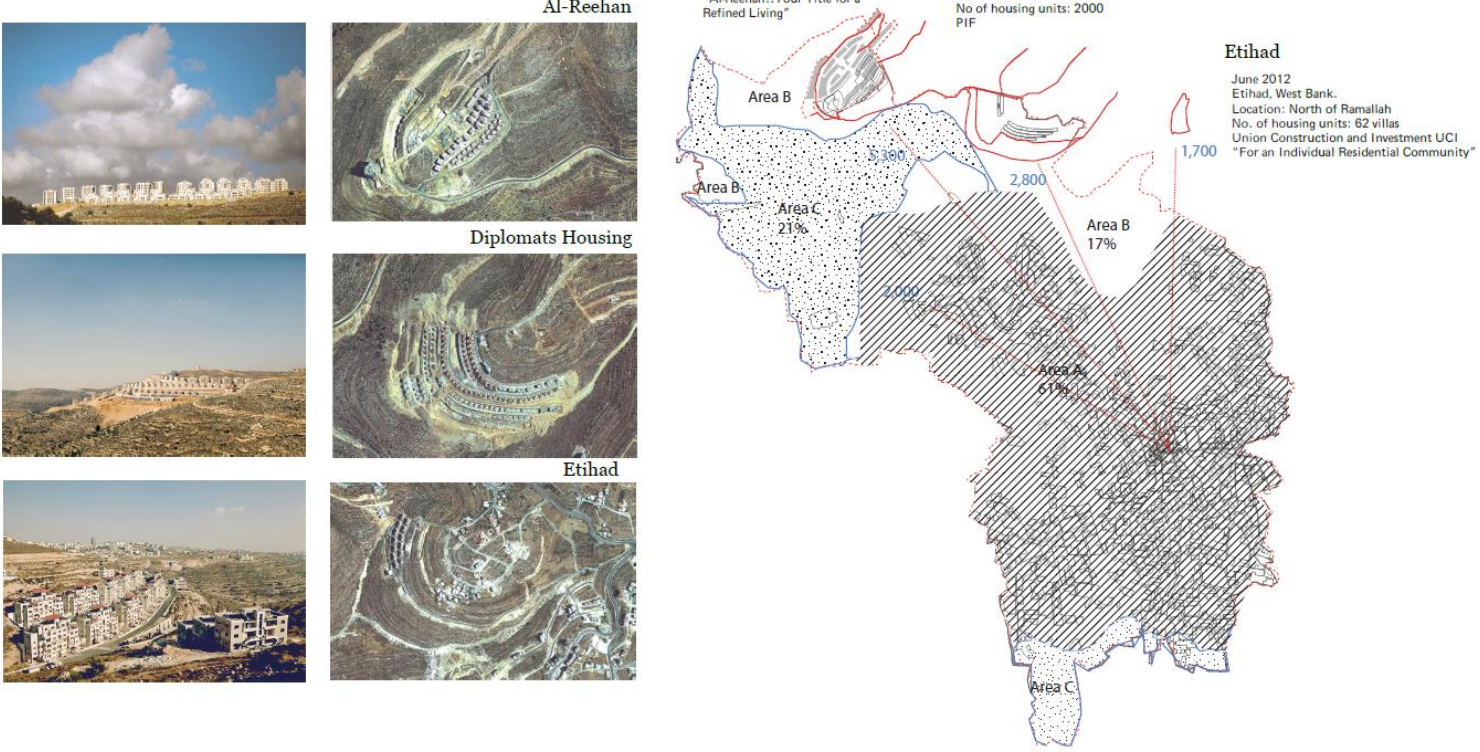

New planned communities around Ramallah: The new planned communities are disconnected by being built on the peripheries and on the hilltops. Their project visions are virtually indistinguishable and follow the very same real estate model, which reproduces many of its architectural typologies and nature. It is a response to the traditional 20th-century desire of middle-class communities to leave the chaotic city centers for the peripheries, seeking security, privacy, and individuality. Image and Diagram Source: Author.

Conflicts of Interest: The author declares no conflict of interest. 